\title{
Sedimentary signatures of tidal bores: a brief synthesis
}

\author{
Bernadette Tessier $^{1}$ (D) $\cdot$ Lucille Furgerot $^{1} \cdot$ Dominique Mouazé $^{1}$
}

Received: 4 July 2016 / Accepted: 24 October 2016

(C) Springer-Verlag Berlin Heidelberg 2016

\begin{abstract}
This article aims at presenting a brief synthesis of sedimentary signatures assigned to tidal bore dynamics and impacts. According to the few studies published until now on tidal bore-induced facies within inner estuarine tidal channel infilling successions, only two major signatures can be reported: (1) soft sediment deformations (SSDs) due to overpressure linked to sudden water level elevation, high shear stress and vertical velocity acceleration below the tidal bore front and secondary waves; SSDs may be present throughout the channel infill succession, with the general exception of the uppermost part; tidal bore-induced SSDs have been described only in modern facies; (2) tidal bore couplets (TBCs) formed by an erosional surface overlain by massive sand drapes, related to the reworking of the sediment bottom during tidal bore passage; TBCs were first described in the ancient record. Studies in modern estuaries demonstrate that TBCs evolve towards tidal bore sequences from the tidal channel bottom (subtidal to low intertidal facies) to tidal channel bank (low to mid intertidal facies). In mid to upper intertidal facies, the occurrence of thicker-thanaverage tidal rhythmites, reflecting higher-than-average suspended sediment concentrations, are also considered as a possible signature of tidal bore dynamics.
\end{abstract}

Responsible guest editor: J.I. Cuitiño

Bernadette Tessier

bernadette.tessier@unicaen.fr

1 Morphodynamique Continentale et Côtière (UMR M2C), Normandie Univ, UNICAEN, UNIROUEN, CNRS, 24 rue des Tilleuls, 14000 Caen, France

\section{Introduction}

Tidal bores are certainly regarded as the most spectacular phenomena occurring in estuarine settings. This hydraulic jump in translation, a few meters high locally, which propagates upstream when the tidal flow turns to rising is known and described for centuries. In many countries it belongs to mythological legends that gave rise to figurative names such as the Silver Dragon in the Qiantang River in China or the Seven Ghost in the Kampar River in Indonesia (see reviews in Lynch 1982; Chanson 2012; Colas 2014).

Until recently, tidal bores were mainly famed for their touristic attractiveness, particularly relayed by surf contests. Although some research works were performed on tidal bores as early as the late XIXth century (see Rousseaux et al. 2016), thorough scientific observations and studies of tidal bores are surprisingly recent, with a tremendous expansion during the last decade through research programs in China (e.g. Pan and Huang 2010; Fan et al. 2012; Huang et al. 2013), France (e.g. Lubin et al. 2010; Mouazé et al. 2010; Bonneton et al. 2011, 2016; Chanson et al. 2011; Simon 2013; Furgerot 2014; Keevil et al. 2015; Furgerot et al. 2016a, b; Rousseaux et al. 2016), the UK (e.g. Simpson et al. 2004; Uncles et al. 2006) and Australia (e.g. Wolanski et al. 2004; Chanson 2012; Khezri and Chanson 2012; Simon 2013). The research includes in situ measurements, experimental approaches and numerical modelling. Due to these numerous and various studies that mainly focus on the conditions of formation, hydrodynamic properties and roles in sediment transport, tidal bores are today much better understood estuarine processes. On the other hand, very few studies have so far been performed on the recognition of tidal bore signatures preserved in sedimentary successions. This is even more odd given the development of 
tide-generated sediment facies models over past decades (see reviews in Davis and Dalrymple 2012; Tessier and Reynaud 2016).

Based on the few works already published, the present paper aims at presenting a synthesis of sedimentary signatures assigned to tidal bores. The discussion includes the consistency of these signatures with the known hydrosedimentary properties of the process.

\section{Overview of tidal bore-related processes}

Tidal bores develop worldwide in many estuaries and tidal rivers (Chanson 2012). Their occurrence depends on a complex balance between the estuary morphology and slope, the tidal range, the incoming tidal flow velocity, the tide asymmetry and the fluvial water discharge (see Bonneton et al. 2016). Generally, well-developed tidal bores form in gently sloping tidal channels of broad funnel-shaped estuary internal areas. Tidal ranges of at least $4 \mathrm{~m}$ (somewhere) downstream of the zone of tidal bore development are required (Lynch 1982; Bonneton et al. 2016).

Depending on water depth and river and tidal flow velocities, two main types of tidal bores exist, undular and breaking. An undular bore comprises a first and main non-breaking wave followed by a series of secondary waves called "whelps". Due to multiple reflections of these waves along channel banks, chaotic shock waves follow the whelp train. A breaking bore is formed by a single breaking roller that in some cases may be followed as well by a series of secondary waves (Junbiao Tu and Daidu Fan, pers. comm.). Tidal bore shape, height (up to a few meters) and front velocity (up to 7-8 $\mathrm{m} / \mathrm{s}$ ) are highly variable in both time and space, according to estuarine conditions. In any case, a tidal bore remains a highly energetic and turbulent process.

In order to discuss the sedimentary signatures assigned to tidal bores, one needs to consider the processes associated with a bore passage (e.g. Furgerot et al. 2013, 2016a, b; Fig. 1), i.e. a sudden rise of the water level accompanied by a flow reversal from downstream to upstream at the water surface as well as at the channel bed (Furgerot et al. 2016b). The time of reversal of the whole water column after the passage is variable depending on the tidal bore development. A quasi-instantaneous total reversal is frequently observed but it may occur up to a few minutes after the passage. The longitudinal velocity reversal is accompanied by a significant upward-directed (vertical) velocity (Fig. 1). These sudden velocity changes imply very high accelerations, the maximum of which is reached prior to and below the front for the upstream (longitudinal) and upward (vertical) velocity respectively. In the case of an undulating bore in the rear of the tidal front, the upstream velocity during the passage of the whelps, while increasing, is subjected to cyclic fluctuations consistent with whelp wavelengths. At the same time, the vertical velocity alternates from upward to downward.

These hydrodynamic properties of tidal bores induce specific impacts in terms of sediment processes. These impacts, which are detailed in the Discussion, include massive reworking of the channel floor accompanied by very high suspended sediment concentrations, particularly immediately above the channel bed below the tidal bore (Fig. 1; Furgerot et al. 2016a).

\section{Sedimentary signatures attributed to tidal bores}

The synthesis proposed herein is necessarily brief as very few studies have been hitherto published that document sedimentary signatures related to the action of tidal bores. These signatures are described both in present-day deposits and rock records, and all are contained in sedimentary successions associated logically with tide-dominated estuarine to tideinfluenced river channel infill. To summarize, two main kinds of sedimentary signatures are described and interpreted as the result of tidal bore action: (1) soft sediment deformations; (2) the association of an erosion surface overlain by draping massive sand.

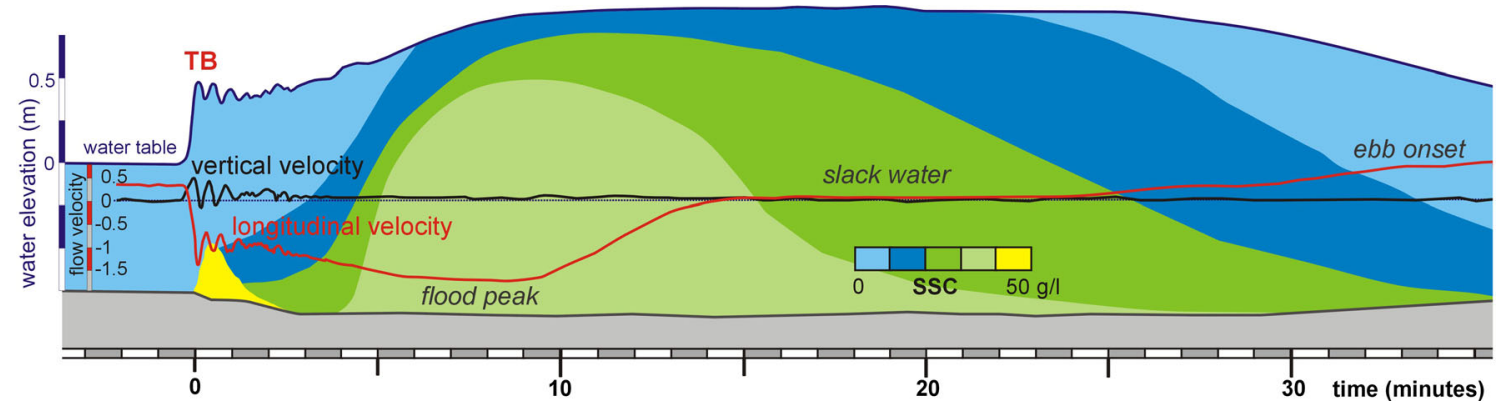

Fig. 1 Main processes related to a tidal bore $(T B)$ passage in terms of flow velocities $(\mathrm{m} / \mathrm{s})$ and suspended sediment concentration $(S S C)$. Strong accelerations of both longitudinal and vertical velocities below the front and secondary waves (whelps) induce erosion of the bottom and a peak of very high SSC. This example is based on measurements in the inner estuary of the Sée River, Mt. St. Michel Bay, NW France (after Furgerot et al. 2016a, b) 


\section{Soft sediment deformations}

Soft sediment deformations (SSDs) are assigned to a variety of environmental settings and driving processes (see review by van Loon 2009). SSDs specifically attributed to the action of tidal bores (TB-SSDs) have been described up to now in modern sediments only (Sée-Sélune estuary, Mt. St. Michel Bay, France, Tessier and Terwindt 1994; Turnagain Arm Estuary, Alaska, Greb and Archer 2007; Qiantang Estuary, China, Fan et al. 2012, 2014, 2015). They are encountered in all types of tidal deposits along bore-affected estuarine channels, from heterolithic sandmud tidal beddings and rhythmites, typifying mid to upper intertidal deposits, to silt- and sand-dominated facies from channel bottoms to lower-mid intertidal settings. Observed TB-SSDs are a few $\mathrm{cm}$ to a few $\mathrm{dm}$ in amplitude, and dm to a few dm in wavelength (Fig. 2a-d). TBSSD structures include mainly contorted beds (convolute) and dewatering structures, indicating that the processes of deformation range from plastic deformation, affecting heterolithic beddings, to liquefaction of silty to sandy facies (Fig. 2c, d). The geometries of contorted beds range from 2D folds with channel-normal axes consistent with the direction of tidal bore propagation, to $3 \mathrm{D}$ chaotic envelops (Fig. 2a, b).

TB-SSDs are explained by the combined effect of processes acting on and in the sediment due to the passage of a tidal bore. These are the overpressure linked to the sudden water elevation, the high shear stress and vertical velocity acceleration below the front. In the case of undular tidal bores, these basic processes are followed by cyclic vertical velocity accelerations due to the whelps. Over-pressurization of rapidly deposited sands in relation with the tidal bore passage can also explain TB-SSDs.

\section{Erosion surface overlain by draping massive sand}

The second type of signature attributed to tidal bore action is represented by a set composed of the two main following elements: (1) a stepped erosion surface overlain by (2) draping massive sand. This couplet "erosion surface / massive sand drape", termed hereafter "tidal bore couplet" (TBC), has been first described and interpreted as the record of tidal bore action in the ancient record (Martinius and Gowland 2011). The depositional environment of the given ancient formation (the Jurassic Lourinha Formation, Lusitanian Basin, western Portugal) is interpreted as a fluvial system modulated by tidal dynamics. The erosion surface is described as undulating, with a series of asymmetric and irregular excavations with relatively short wave length (a few $\mathrm{dm}$ ) and high amplitude (up to $15 \mathrm{~cm}$ deep; Fig. 3a). Its lateral extent is relatively low (10 $\mathrm{m}$ max. on outcrop). The overlying draping sands are massive with a very homogeneous grain-size distribution. Locally, they contain some lamination dipping upstream. These TBCs, decimetric in thickness, are rare in the studied formation and encased within downstream-migrating fluvial sand bodies (Fig. 3a).

In the modern record, very similar TBCs have been identified and described afterwards by Fan et al. (2012, 2014, 2015), in sediment cores collected along the channel bank of the Qiantang Estuary (China). The massive sands are described as slightly coarser and better sorted than adjacent regular tidal sands. The better sorting is consistent with the observation by Martinius and Gowland (2011). Modern TBCs are frequently observed intercalated into low to mid intertidal heterolithic facies in the inner estuary of the Mt. St. Michel Bay, NW France (e.g. Fig. 3b, c).

Another example of TBCs preserved in the rock record is provided by Fielding and Joeckel (2015). The palaeo-
Fig. 2 Soft sediment deformations (SSDs) attributed to tidal bore impact (mid intertidal facies, Sée-Sélune estuary, Bay of Mt. St. Michel, NW France). a 2D folded deformed surface along a tidal channel. The fold axes are consistent with tidal bore propagation (perpendicular). $\mathbf{b}$ 3D deformed surface along a tidal channel. c Cross-section of a highly deformed succession. d Cross-section of a deformed succession showing contorted beds (plastic deformation) and massive sands (liquefaction). a-c Knife for scale: $40 \mathrm{~cm}$ long. $\mathbf{d}$ Scale bar in cm
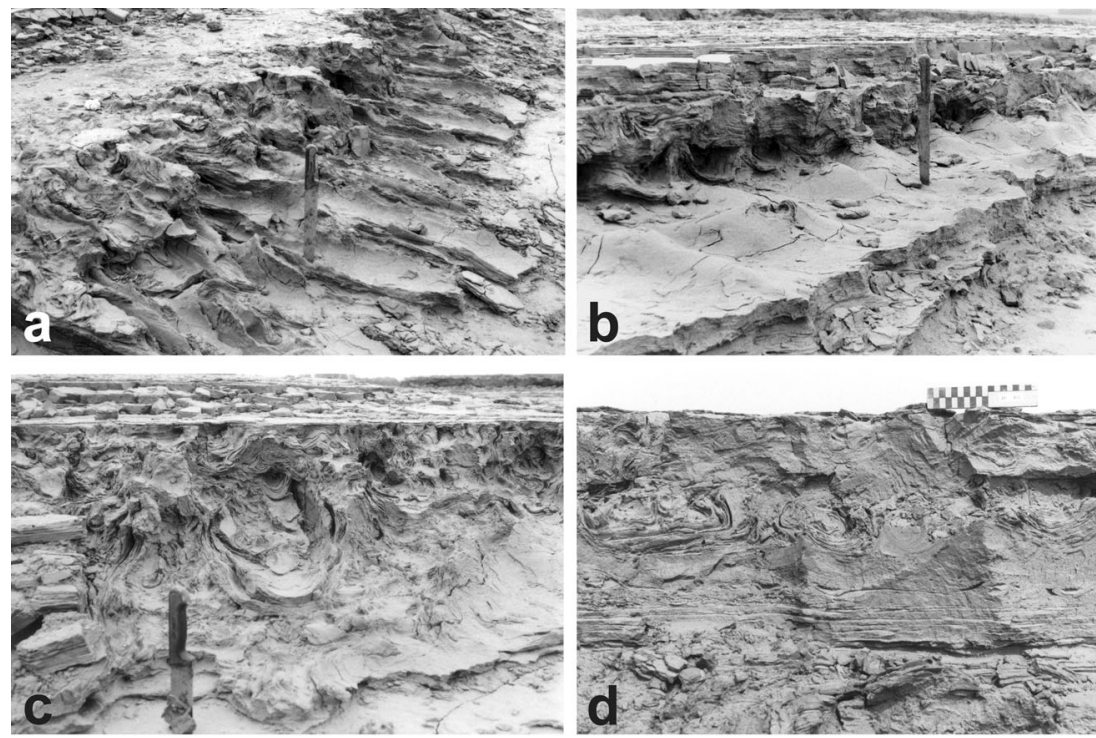

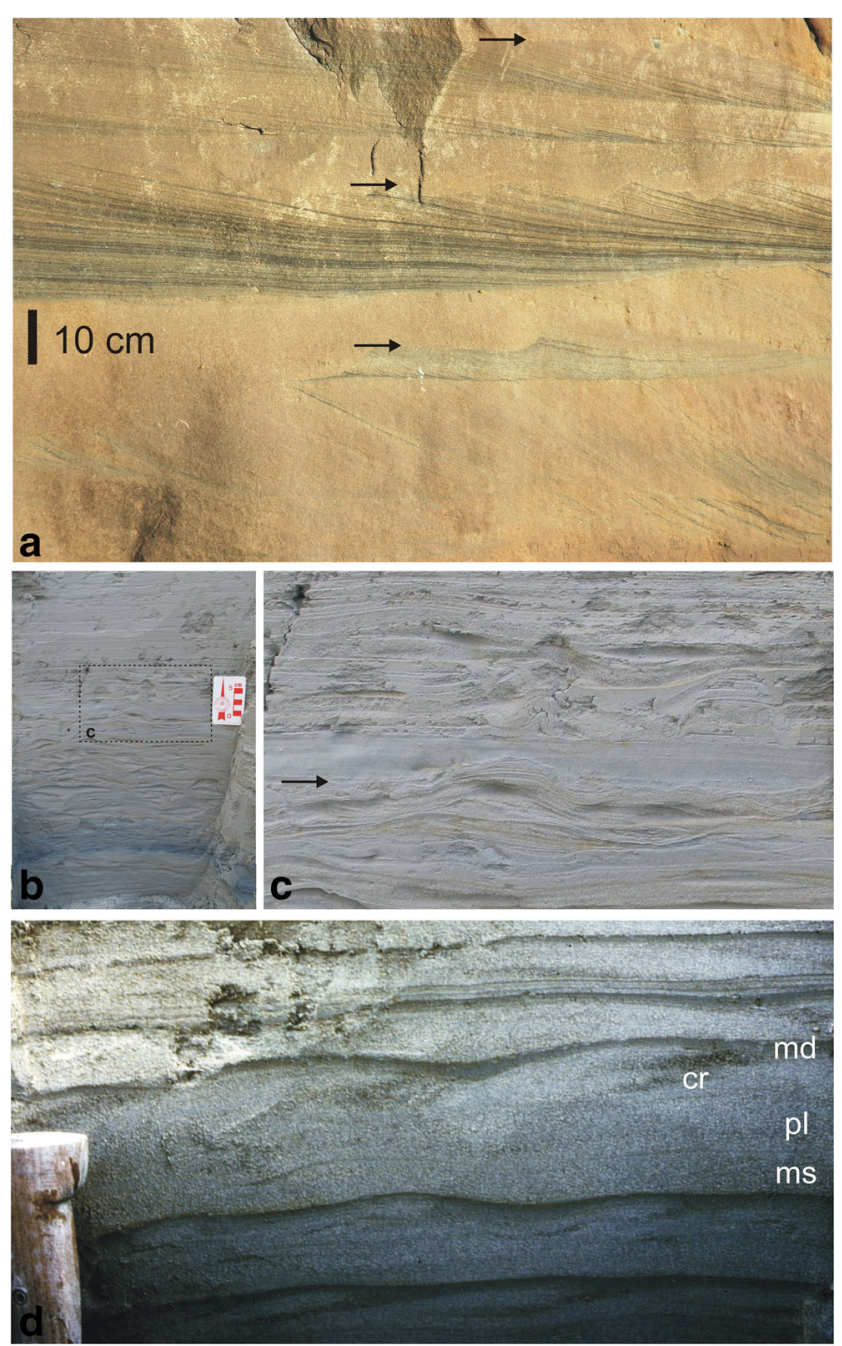

Fig. 3 Photographs illustrating a tidal bore couplet (TBC) and tidal bore sequence (TBS). a TBC intercalated within fluvial dominated sands (Jurassic Lourinha Formation, Lusitanian Basin, western Portugal; photo courtesy of Allard Martinius). Arrows Basal erosional surface of TBC, overlain by massive sands. b Low to mid intertidal facies succession mostly formed by typical tidal bedding. A TBC (arrow erosional base) is intercalated within the middle part (inner estuary of Sélune River, Bay of Mt. St. Michel, NW France). $\mathbf{c}$ Detail of $\mathbf{b}$, focussing on the TBC. d Mid intertidal facies including complete TBS comprising above a sharp basal surface, massive sand $(m s)$, UFR planar bedding $(p l)$, climbing ripple $(c r)$ and finally a mud drape $(m d)$; (inner estuary of Sélune River, Bay of Mt. St. Michel, NW France). Knife handle: $12 \mathrm{~cm}$

environment of the studied succession (the Pennsylvanian Indian Cave Sandstone, Echo Cliff, NE Kansas, USA) is interpreted as a tide-influenced fluvial system. These fossil TBCs show many similarities with those described by Martinius and Gowland (2011) in the Jurassic record, and Fan et al. $(2012,2014)$ in the Qiantang Estuary. One may note the following specific features: the erosion surface is reworked into symmetrical and asymmetrical ripples, and the draping sands are muddy or rich in plant debris. This last point differs somewhat from the observations of
Martinius and Gowland (2011) and Fan et al. (2012), who described clean, well-sorted draping sands. Fielding and Joeckel (2015) explained this fact by local specificities of channel bed sediments. By combining the elements provided by these different authors and their observations, Fielding and Joeckel (2015) proposed a facies model to identified tidal bore deposits, fundamentally TBCs.

In terms of interpretation in relation with tidal bore processes, basically the erosion surface is interpreted as the result of scouring due to the tidal bore front and whelps and associated stress reversals, while the massive draping sands result from the rapid deposition of suspended sediment after the bore passage.

\section{Discussion}

Recent works on tidal bores in modern settings, focussing either on their hydro-sediment dynamic properties (e.g. Furgerot et al.2016a) or on the specific sedimentary facies they induce (e.g. Fan et al. 2014, 2015), provide very useful information for developing a more comprehensive description and for reaching a better understanding of sedimentary facies association that could be related to tidal bore-affected environments. In the Qiantang deposits, Fan et al. $(2014,2015)$ attribute indeed more complete sediment packages than simple TBCs to tidal bore action. In many of the cores collected along the intertidal banks of the estuary, the massive sands that rest above the erosion surface pass upwards to sandy parallel lamination and then convolute bedding. Lanier and Tessier (1998) described fairly similar packages in mid intertidal channel bank deposits of the Sélune internal estuary (Mt. St. Michel Bay, NW France), where tidal bores commonly develop during spring tides. There, individual sequences up to $10 \mathrm{~cm}$ thick show a succession comprising massive sand resting on a sharp surface, followed by upper flow regime (UFR) planar bedded sand, passing upwards to flood-deposited climbing ripple bedded sand and evolving finally into a fine-grained silty drape (Fig. 3d). Lanier and Tessier (1998) interpreted this sequence as a single flooddominated tidal couplet, attributing the flood-generated climbing ripple bedding interval to very high concentration of suspended sediment in relation to the tidal bore passage in the channel and the sudden submersion of the tidal channel bank (flood tide levee).

The works of Furgerot et al. (2016a, b) detail the evolution of flow velocities and suspended sediment concentration (SSC) specifically associated with the passage of a tidal bore in a tidal channel. They demonstrated that, below the front simultaneously to the flow inversion that arises first at the bottom, an instantaneous erosion (few cm deep) of the channel 
bed occurs, together with very high SSC (a few tens of g/l) just above the bed (Fig. 1). During the few tens of seconds following the front passage, this very high peak of SSC decreases, whereas in the whole water column SSC progressively raises from a few $\mathrm{g} / \mathrm{l}$ to a few tens of $\mathrm{g} / \mathrm{l}$ as the flood velocity increases until a maximum that is reached a few minutes after the tidal bore passage. The flood starts to slow down while SSC remains very high before it decreases significantly at the slack water stage.

The sequence described by Lanier and Tessier (1998) can be put in parallel with the succession of processes previously described. The basal massive sand bed records the very rapid, almost immediate deposition of the sediment reworked at the bottom below the tidal bore front. The UFR planar laminated bed records the maximum flood velocity and the climbing ripple bedding interval reflects the deceleration onset, both with very high SSC. The finer-grained draping top bed is deposited during slack water. This succession, from the basal erosional surface to the draping unit, including the massive sand (UFR planar laminae) climbing ripple bed, can be referred to as a tidal bore sequence (TBS; Fig. 3).

Tidal bore couplets (TBCs), such as described by Martinius and Gowland (2011) and Fielding and Joeckel (2015), can be considered as the basal part of a TBS. TBSs can probably be deposited at the bottom of a channel but, due to the high erosional impact of tidal bores, their preservation potential is there very reduced, and only the basal part is thus preserved. In the ancient record, Chamizo-Borreguero et al. (2016) provided another example of putative tidal bore sedimentary records encased within ephemeral alluvial and overbank deposits (Utrillas Formation, Albian, Iberian Basin, Serranía de Cuenca sub-basin, eastern Spain). They described successions of tabular sandstone beds with low angle planar lamination. These successions infill steep erosional incisions, up to $9 \mathrm{~m}$ deep. The bases of individual beds are flat to slightly undulating erosional surfaces. Sands are very well sorted. One may assume that such thick sanddominated tidal bore facies correspond to amalgamated TBCs preserved as channel bottom infilling.

Based on their observations in the Qiantang Estuary, Fan et al. $(2014,2015)$ proposed a schematic model of distribution of tidal bore-induced facies according to the position of deposition with respect to the tidal channel axis and elevation. The model highlights the evolution from TBCs preserved in subtidal to lower intertidal facies (channel bottom) towards more complete packages preserved in lower to mid intertidal facies and corresponding to TBSs. Tidal bore-induced soft sediment deformations can occur throughout the succession.

In this model by Fan et al. (2012, 2014, 2015), mid to upper intertidal heterolithic facies, generally preserving tidal rhythmites and typical of the upper part of a channel infill sequence, are regarded as regular tidal deposits, i.e. non tidal bore-affected facies. Observations along the Sée and Sélune rivers (Mont Saint Michel Bay, France), however, show that tidal rhythmites comprised in the mid to upper intertidal channel bank deposits are locally formed by extremely thick individual tidal couplets resulting necessarily from SSCs much higher than normal, certainly due to tidal bores. It is thus concluded that mid to upper tidal rhythmites can also record tidal bore dynamics; tidal bore-related rhythmites are much thicker than average (Figs. 4 and 5).

In the model by Fan et al. (2014, 2015), tidal boreinduced soft sediment deformations (TB-SSDs) are positioned within lower to middle intertidal deposits, affecting
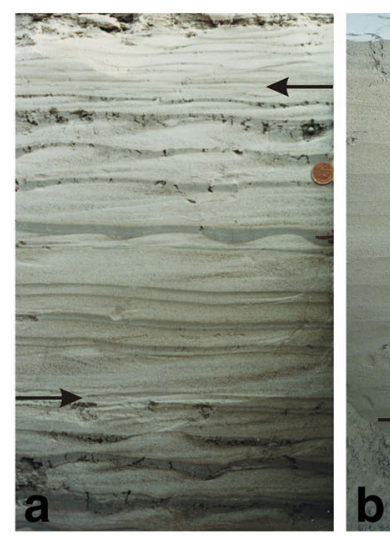

Fig. 4 Thicker-than-average middle to upper intertidal rhythmites attributed to high suspended sediment concentration induced by tidal bores: a thick tidal rhythmites including complete tidal bore sequences as tidal couplets (Sélune River inner estuary, Bay of Mt. St. Michel, NW France; coin for scale: $1 \mathrm{~cm}$ ); b tidal rhythmites made of thick planar

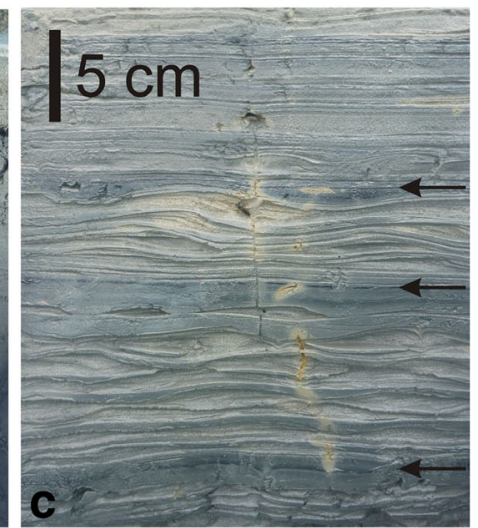

bedded sand-dominated tidal couplets (flood tidal levee, Sée River inner estuary, Bay of Mt. St. Michel, NW France). c For comparison, typical averaged thick tidal rhythmites (Sélune River inner estuary, Bay of Mt. St. Michel, NW France; Tessier 1993). Arrows on all photos Neap tide period (emersion a few days long) 


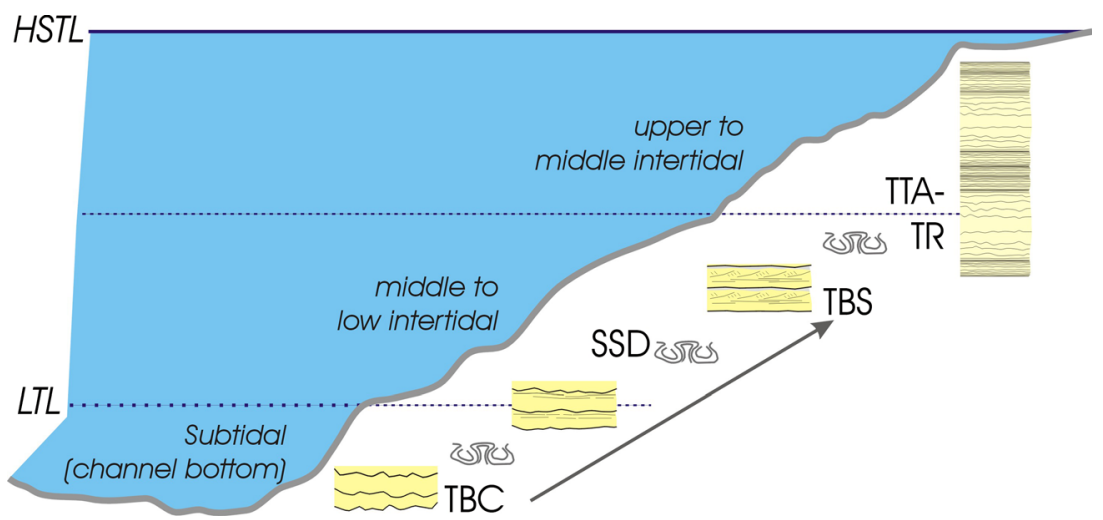

Fig. 5 Schematic distribution of tidal bore sedimentary signatures that can be preserved in a tidal channel infilling succession, from tidal bore couplets (TBCs) within subtidal facies to tidal bore sequences (TBSs) within low to mid intertidal facies. Very high SSC due to tidal bores produce thicker- than-average tidal rhythmites (TTA-TRs) preserved in mid to upper intertidal facies. Tidal bore-induced soft sediment deformations (SSDs) can be present throughout the succession, except in the upper intertidal part. LTL Low tide level, HSTL high spring tidal level the top of TBCs and TBSs. Middle to upper regular tidal bedding and rhythmites are not considered to be impacted by TB-SSDs (Fig. 5). Although observations in the Bay of Mt. Saint Michel clearly show that regular tidal rhythmites can be deformed as well due to tidal bore passages (Tessier and Terwindt 1994), the model of Fan et al. $(2014,2015)$ is consistent with the results of experimental works performed in flumes to reproduce TB-SSDs (Furgerot 2014; Furgerot et al. 2015). These experiments demonstrate that vertical up and down velocity changes alone do not induce convolute deformations. A high shear stress is necessary as well. This means that TB-SSDs can be produced only where tidal bores have a direct impact on the sediment bed, both with significant longitudinal and vertical components. Such an impact does not occur in upper parts of intertidal channel banks that are generally gently flooded a few minutes after the tidal bore passage.

Finally, it is worth noting that no SSDs have been described and assigned so far in rock records to tidal bore impacts. Neither Martinius and Gowland (2011), nor Fielding and Joeckel (2015), nor Chamizo-Borreguero et al. (2016) mentioned the occurrence of SSDs adjacent to the facies they attribute to tidal bore dynamics. This could be due to a problem of recognition, since all the given studied formations are sand dominated.

Anyhow, soft sediment deformations of various origins are very common features both in modern and ancient tidal deposits (Greb and Archer 2007). This certainly implies that not all SSDs affecting estuarine tidal facies can be interpreted as tidal bore-generated features. To be assigned to tidal bores, SSDs should be encased in nondeformed tidal deposits, more specifically in tidal bedding or tidal rhythmites, and should display characteristics such as their orientation being consistent with tidal bore propagation (cf. Fig. 2a), allowing to exclude slumps or earthquake-generated deformations. Such combined criteria are difficult to observe on outcrops. It is thus probable that, in some ancient examples due to a lack of such criteria, a tidal bore interpretation has not been proposed. As an example, Plink-Björklund (2005) described the occurrence of abundant SSDs in tidal facies deposited in a tide-dominated estuarine environment (Eocene Central Basin, Spitsberg). One may suggest that some of these SSDs are TB-SSDs.

\section{Conclusions}

- A variety of sedimentary facies can be attributed to tidal bore processes, mainly depending on the position with respect to the axis of the channel in which the bore propagates. These facies range from tidal bore couplets (TBCs) in the channel axis to tidal bore sequences (TBSs) in lower to mid intertidal bank facies, and to much thicker-than-average tidal couplets in middle to upper intertidal deposits.

- These signatures record the direct impact of tidal bores on the sediment bottom (TBC, SSD) as well as their indirect impact, in relation mainly with the very high SSC induced by the tidal bore passage (complete TBS with climbing ripples, thicker-than-average tidal couplets in tidal rhythmites).

- Compared to regular tidal facies, tidal bore-induced sedimentary signatures represent conspicuous features encased in tidal channel infilling successions, facilitating their recognition.

Acknowledgements This paper is a contribution to the ANR project "Mascaret", the coordinator of which, Prof. Pierre Lubin, is warmly thanked. We gratefully acknowledge the constructive criticisms and comments of Daidu Fan, Christopher Fielding, as well as Jose Cuitiño, the 
guest editor of this special issue, and the journal editors. We thank Allard Martinius who kindly provided the photo included in Fig. 3.

\section{Compliance with ethical standards}

Conflict of interest The authors declare that there is no conflict of interest with third parties.

\section{References}

Bonneton P, Van de Loock J, Parisot JP, Bonneton N, Sottolichio A, Dedandt G, Castelle B, Marieu V, Pochon N (2011) On the occurrence of tidal bores - The Garonne River case. J Coast Res SI 64: 1462-1466

Bonneton P, Filippini AG, Arpaia L, Bonneton N, Ricchiuto M (2016) Conditions for tidal bore formation in convergent alluvial estuaries. Estuar Coast Shelf Sci 172:121-127

Chamizo-Borreguero M, Melendez N, De Boer P (2016) Tidal-bore deposits in incised valleys, Albian, SW Iberian Ranges, Spain. In: Tessier B, Reynaud JY (eds) Contributions to modern and ancient tidal sedimentology. IAS spec publ 47:89-111

Chanson H (2012) Tidal bores, Aegir, Eagre, Mascaret, Pororoca: theory and observations. World Scientific, Singapore

Chanson H, Reungoat D, Simon B, Lubin P (2011) High-frequency turbulence and suspended sediment concentration measurements in the Garonne River tidal bore. Estuar Coast Shelf Sci 95:298-306

Colas A (2014) Mascaret, l'onde lunaire. Editions Cairn

Davis RA, Dalrymple RW (eds) (2012) Principles of tidal sedimentology. Springer, Heidelberg

Fan DD, Cai GF, Shang S, Wu YJ, Zhang YW, Gao L (2012) Sedimentation processes and sedimentary characteristics of tidal bores along the north bank of the Qiantang Estuary. Chin Sci Bull 57:1578-1589

Fan DD, Tu J, Shang S, Cai G (2014) Characteristics of tidal bore deposits and facies associations in the Qiantang estuary, China. Mar Geol 348:1-14

Fan D, Shang S, Cai G, Tu J (2015) Distinction and grain-size characteristics of intertidal heterolithic deposits in the middle Qiantang Estuary (East China Sea). Geo-Mar Lett 35:161-174. doi:10.1007 /s00367-015-0398-2

Fielding CR, Joeckel RM (2015) Recognition of tidal-bore deposits in the rock record: towards a facies model. J Sediment Res 85:118-123

Furgerot L (2014) Propriétés hydrodynamiques du mascaret et de son influence sur la dynamique sédimentaire. Une approche couplée en canal et in situ (estuaire de la Sée, Baie du Mont Saint Michel). $\mathrm{PhD}$ dissertation, University of Caen, Normandie. https://tel. archives-ouvertes.fr/tel-01061118

Furgerot L, Mouazé D, Tessier B, Perez L, Haquin S (2013) Suspended sediment concentration in relation to the passage of a tidal bore (See River estuary, Mont Saint Michel Bay, NW France). In: Bonneton P, Garlan T (eds) Proc Coastal Dynamics 2013, pp 671-682

Furgerot L, Tessier B, Mouazé D, Perez L, Haquin S, Poprawski Y (2015) Processes involved in the genesis of soft-sediment deformation related to tidal bore passage. In: Abstr Vol 9th Int Conf Tidal Sedimentology, Tidalites 2015, 10-13. http://tidalites2015.com. ar/pdf/TIDALITES\%202015.pdf\#zoom=100

Furgerot L, Weill P, Mouazé D, Tessier B (2016a) Suspended sediment dynamics induced by the passage of a tidal bore in an upper estuary. In: Tessier B, Reynaud JY (eds) Contributions to modern and ancient tidal sedimentology. IAS spec publ 47:57-70
Furgerot L, Mouazé D, Tessier B, Perez L, Haquin S, Weill P, Crave A (2016b) Sediment transport induced by tidal bores. An estimation from suspended matter measurements in the Sée River (Mont-SaintMichel Bay, northwestern France). CR Geoscience 348:432-441

Greb SF, Archer AW (2007) Soft-sediment deformation produced by tides in a meizoseismic area, Turnagain Arm, Alaska. Geology 35: 425-438

Huang J, Pan CH, Kuang CP, Zeng J, Chen G (2013) Experimental hydrodynamic study of the Qiantang River tidal bore. J Hydrodyn $25: 481-490$

Keevil CE, Chanson H, Reungoat D (2015) Fluid flow and sediment entrainment in the Garonne river bore and tidal bore collision. Earth Surf Process Landf 40:1574-1586

Khezri N, Chanson H (2012) Inception of bed load motion beneath a bore. Geomorphology 153-154:39-47

Lanier W, Tessier B (1998) Climbing ripple bedding in fluvio-estuarine system; a common feature associated with tidal dynamics. Modern and ancient analogues. In: Alexander C, Davis RA Jr, Henry VJ (eds) Tidalites: Processes and products. SEPM spec publ 61:109-117

Lubin P, Glockner S, Chanson H (2010) Numerical simulation of a weak breaking tidal bore. Mech Res Commun 37:119-121

Lynch DK (1982) Tidal bores. Sci Am 247:146-156

Martinius AW, Gowland S (2011) Tide-influenced fluvial bedforms and tidal bore deposits (Late Jurassic Lourinhã Formation, Lusitanian Basin, Western Portugal). Sedimentology 58:285-324

Mouazé D, Chanson H, Simon B (2010) Field measurements in the tidal bore of the Sélune River in the Bay of Mont Saint Michel (September 2010). The University of Queensland, Brisbane

Pan C, Huang W (2010) Numerical modeling of suspended sediment transport affected by tidal bore in Qiantang Estuary. J Coast Res 26:1123-1132

Plink-Björklund P (2005) Stacked fluvial and tide-dominated estuarine deposits in high-frequency (fourth-order) sequences of the Eocene Central Basin, Spitsbergen. Sedimentology 52:391-428

Rousseaux G, Mougenot J-M, Chatellier L, David L, Calluaud D (2016) A novel method to generate tidal-like bores in the laboratory. European J Mechanics B Fluids 55:31-38

Simon B (2013) Effects of tidal bores on turbulent mixing: a numerical and physical study in positive surges. $\mathrm{PhD}$ dissertation, Université Sciences et Technologies, Bordeaux I, France \& University of Queensland, Australia. https://tel.archives-ouvertes.fr/tel-00965582

Simpson JH, Fisher NR, Wiles P (2004) Reynolds stress and TKE production in an estuary with a tidal bore. Estuar Coast Shelf Sci 60: 619-627

Tessier B (1993) Upper intertidal rhythmites in the Mont-Saint-Michel Bay (NW France): perspectives for paleoreconstruction. Mar Geol 110:355-367

Tessier B, Reynaud JY (eds) (2016) Contributions to modern and ancient tidal sedimentology. An introduction to the volume. IAS spec publ 47:1-4

Tessier B, Terwindt JHH (1994) An example of soft-sediment deformations in an intertidal environment: the effect of tidal bores (in French with extended English abstract). CR Acad Sci 319:217-223

Uncles RJ, Stephens JA, Law DJ (2006) Turbidity maximum in the macrotidal, highly turbid Humber Estuary, UK: flocs, fluid mud, stationary suspensions and tidal bores. Estuar Coast Shelf Sci 67: $30-52$

van Loon AJ (2009) Soft-sediment deformation structures in siliciclastic sediments: an overview. Geologos 15:3-55

Wolanski E, Williams D, Spagnol S, Chanson H (2004) Undular tidal bore dynamics in the Daly Estuary, Northern Australia. Estuar Coast Shelf Sci 60:629-636 